\title{
Community, virtue and the White British poor
}

Dialogues in Human Geography 2016, Vol. 6(I) 50-68 (C) The Author(s) 2015 Reprints and permission: sagepub.co.uk/journalsPermissions.nav DOI: 10.1 | 777/20438206/5624603 dhg.sagepub.com

@SAGE

\section{Michael S Merry}

University of Amsterdam, the Netherlands

\section{David Manley}

University of Bristol, UK

\section{Richard Harris \\ University of Bristol, UK}

\begin{abstract}
Whilst media and political rhetoric in Britain is sceptical and often outright damning of the (presumed) morals and behaviours of the White marginalized poor, our aim is to explore the conditions under which successful communities are nevertheless built. Specifically, we examine the features of community and stress its importance both for belonging and bonding around shared norms and practices and for fostering the necessary bridging essential for interacting and cooperating with others. In considering what it means to foster a community that acts as a breakwater against the tides of stigma or disadvantage, we pay special attention to what we will call enabling conditions - essential features that communities either can or should be able to provide or that exist independent of communities and are indispensable for accessing opportunities in the wider society. We detail the dynamics of White poverty and exclusion before turning our attention to possible responses to these challenges. In searching for viable responses to stigma and disadvantage, we compare some different typologies of community presently available to the White poor in Britain and examine whether these are sufficient to satisfy the enabling conditions associated with more robust forms of group membership.
\end{abstract}

\section{Keywords}

Britain, community, enabling conditions, virtue, White poor

A cornerstone of the Conservative vision of Big Society is the need to have well functioning and responsible communities that provide the necessary framework within which individuals and groups can gain the resources that they need to thrive. Such resources are immediately available to more affluent groups but for the White marginalized poor there is a double disadvantage. First, the nature of their economic conditions leaves them vulnerable and less well-positioned to provide the community

\section{Corresponding author:}

Michael S. Merry, Faculty of Social and Behavioral Sciences, University of Amsterdam, Amsterdam $1012 \mathrm{WX}$, the Netherlands.

Email: m.s.merry@uva.nl 
support that the idea of Big Society entails. Second, the group in question often faces ridicule and demonisation within the media and by politicians for their (alleged) behaviours such as a culture of worklessness (Flint, 2003; Hancock and Mooney, 2013; Rose, 2000). Strong and successful communities are posited as the cornerstone of a socially caring society, but the pejorative rhetoric applied to the marginalized poor implies that the 'communities' available to this group lack role models and the sort of social glue that politicians seek to promote. Increasingly treated as 'leeching' on a welfare system already under tremendous strain, controversial media portrayals such as (British) Channel Four TV's Benefits Street add to the impression that this is a group displaced and unwelcomed by the mainstream, or out of tune, at least, with the social and civil values of the wider society. ${ }^{1}$

The White poor are, of course, not the only group facing challenging economic conditions. In the wake of the 2008 recession and the politics of austerity, a dramatically larger portion of the European population find themselves excluded from the scarce work and career opportunities that remain, whilst at the same time, vulnerable to the retrenchment of the welfare state. This ever expanding demographic group increasingly finds itself unable to find employment. Making matters worse, they often lack the education, training and skills needed to fill the better paying positions higher up the economic ladder. ${ }^{2}$ Those who can rely on their families or neighbours, do so. Others, less fortunate and perhaps destitute, are pushed into shelters, food banks or onto the street. A variety of downward spiralling circumstances and, concomitantly, limited choices may ensue for those with no community to call their own. Members of visible minority groups, among them recent immigrants and asylum seekers, are particularly vulnerable to stigma. But so, too, are members of the dominant ethnic group - the White British. ${ }^{3}$ The difference is that the White poor may be one of the last remaining groups whom it is possible to publicly blame, castigate and ridicule with impunity.

In response, and in this article, we examine the ideas of community and virtue as they may apply to the White marginalized poor in Britain. We focus on this group for several reasons. First, unlike in many other European countries, the role of social class in British society has played an important part in demarcating entire sectors of the White majority. Second, deindustrialization coupled with dramatic policy shifts in the United Kingdom and beyond during the last 35 years have sharpened these class differences in ways that arguably are more pronounced in the British context. Third, there is an existing literature about the White working class and White poor, which in recent years has inclined towards a discourse of a culture of poverty and even an 'underclass' - a description that comes in and out of fashion (see also Murray et al., 1996; Welshman, 2013; Wilson, 1984). Finally, as we have articulated, many labelled as White poor in the British context deal with a stigma and class prejudice every bit as prejudicial and discriminatory in tone as that more typically reserved for members of other visible and stigmatized minority groups (Jones, 2012; McIntyre and McKee, 2008; Slater, 2012; Valentine and Harris, 2014).

We tackle these sensitive issues, employing community as a framing device. Specifically, we examine the features of community and stress its importance both for belonging and bonding around shared norms and practices and for fostering the necessary bridging essential for interacting and cooperating with others. We enlist community in our analysis for three reasons. First, notwithstanding its inherent plasticity, its staying power is undisputed. As Hancock et al. (2012: 345) write, 'community carries an intense attraction for a wide set of interested parties - social theorists, politicians, policy-makers, service providers, practitioners and it has a "folk" appeal'. Thus, whatever vagueness a concept like 'community' may suffer from, politicians and policymakers routinely enlist the concept in countless ways and its appeal continues to resonate across ideological lines.

Second, community implies both a strong spatial and a moral dimension. Spatially, communities typically are divided by location on the basis of things like religion, ethnicity and socio-economic status. Communities may therefore instantiate highly unequal access to resources relevant to their flourishing. Indeed, if personal networks are one way 
to access valuable resources, 'spatial segregation thus negatively affects people's opportunities to gain resources and thus to improve their socioeconomic position' (Van Eijk, 2010: 469). And here we can see a nexus to its moral dimension, for in the mouths of some critics, the elements of community represent a kind of moral ideal. Hancock et al. (2012: 355) explain, 'While community is valorized as a solution and counter to the broken society, community is at the heart of a vilifying narrative of particular and multiply flawed communities. In this respect there is a particular geography at work here, too'. Indeed, spatial concentrations of certain groups can reinforce 'territorial stigmatization' (Hancock and Mooney, 2013; McKenzie, 2015; Wacquant, 2008).

Third, community matters for our analysis because under punishing and involuntary circumstances, members of stigmatized groups often turn inward. That is, many look to their own communities for support. Shared experiences with adversity assist with coping but also pragmatically with forging new and hybrid forms of solidarity with other members of their group. What may be lacking in social or economic prosperity may be compensated for in other ways: that is, communities often facilitate both commonalities and support along the lines of cultural or social class background, religion, language and, quite simply, minority status. ${ }^{4}$ Therefore, communities can serve to buffer members of vulnerable groups against the difficulties and discrimination they routinely face. This is not to say that all disadvantaged groups are stigmatized equally or those that are will respond in identical or equally effective ways. Much will depend on the characteristics of the group in question. Nevertheless, the presence of residency concentrations, cultural congruence with the mainstream, social networks and institutional supports can assist in enabling and facilitating resilience. Critically, each of these importantly contributes to what makes communities work.

Meanwhile, for poor and stigmatized members of the dominant ethnic group, the indications of social exclusion may not seem so obvious. After all, in terms of nationality, ethnicity or first language, members of this demographic group may be privileged relative to other visible, and stigmatized, minorities. Yet the reality suggests a more complex picture. For example, in a number of important respects, those belonging to a large and amorphously defined demographic group of White poor not only occupy a marginal position in many societies, they may actually be doubly disadvantaged. That is to say, opportunities for turning inward for support from one's community - analogous to that of other groups - appear to be fragmented if not absent. Indeed, previous types of solidarity - trade unions, for example - that once were prevalent have been greatly reduced. Other crucial forms of community - the Church, for instance - too have eroded. Populists have little difficulty in seizing upon a resulting sense of abandonment or disenfranchisement and channelling it into rage directed at the political establishment (or, in extreme cases, at other ethnic groups).

In considering what it means to foster community that acts as a breakwater against the tides of stigma or disadvantage, we pay special attention to what we will call enabling conditions - essential features that communities either can or should be able to foster and secure for themselves or that exist independent of communities yet are accessible to those who need them. Either way, enabling conditions, we argue, are indispensable for accessing opportunities in the wider society. We then provide some background description of the group in question and delineate a number of real challenges they face. To be sure, many of these challenges are economic. Driven by capitalist modes of production and property distribution, highly unequal opportunities in education and the labour market are no longer circumscribed by national boundaries; indeed more persons than ever before increasingly are impacted by global economic realities. So ours is an investigation into the crucial role that communities play but particularly whether communities in any meaningful sense are still available to the White poor of Britain in the 21 st century. If not, then this suggests that such groups are doubly disadvantaged within a policy context wherein the government and other policy institutions turn to communities to provide help for themselves. 
In what follows, we first examine the features of community, noting both its inclusive and exclusive elements, before examining the potential virtues that communities produce. Here we make use of Robert Putnam's bonding and bridging notions of social capital. $^{5}$ Following this, we detail the dynamics of White poverty and exclusion before turning our attention to possible responses to these challenges. In searching for viable responses to stigma and disadvantage, we compare some different typologies of community presently available to the White poor in Britain and examine whether these are sufficient to satisfy the enabling conditions associated with more robust forms of group membership.

In short, the article presents a theory of successful communities distinguished as a space of belonging in which some sense of virtue is fostered among its members. Whilst media and political rhetoric is sceptical and often outright damning of the (presumed) morals and behaviours of the marginalized poor, our aim is to explore the conditions under which successful communities are nevertheless built.

\section{Community}

A community can be described as a collection of persons whose characteristics are defined by shared interests, values, beliefs and concerns. Traditionally, a community entails a shared location - a coming together in a specific place that is to some extent made one's own. Although nowadays it is common to speak of online communities, in this article, our discussion largely presumes a presence and activity in a physical location. Communities also are typically understood to share a common identity. Of course, what is shared may camouflage considerable internal variation. However, many communities exhibit shared commitments, goals and concerns that transcend the heterogeneous identities its members possess. Once established, communities cohere around shared norms, understandings and experiences and with the right leadership and facilitating conditions are able to direct the attention and energies of its members towards common ends. With its shared interests and concerns, communities can significantly mitigate the pangs of privation, isolation and exclusion.

Fundamentally, community is about belonging. By its very definition, it is set in opposition to isolation. Temporary isolation can of course be important, providing relief from the pressures and expectations of others; isolation, too, can offer one the space, peace and quiet necessary to reflect, imagine and heal. Yet whilst isolation is able to play this therapeutic role in all of our lives, many people also yearn for some kind of community to which they can belong. Strike (2010: 44) observes:

A sense of belonging both aids and is aided by normation. That we are included, that we belong, is a significant factor in our willingness to internalize the norms of a community. That we internalize these norms also becomes a factor in our inclusion. Community begins in learning the norms of those who care for and about us, and ends in caring for and about those whose norms we share.

Notwithstanding its obvious appeal, none of the foregoing offers us much in the way of assessing communal norms. After all, communities as such are not morally neutral. Constructing and maintaining a community typically involves as much exclusion as it does inclusion, although the former may not be intended. Boundaries must be drawn and criteria delineated; rules and expectations ensue. Community members may understand their group's identity for what it is not as much as for what it is. Communities also may harbour internal restrictions hidden from public view. Even marginalized and oppressed communities often embody hierarchical privileges for their more dominant members. Internal restrictions directed against women, homosexuals, the disabled or even those of minority opinion may lead to some experiencing discrimination or abuse from within their 'own' group (Eisenberg and Spinner-Halev, 2005). Indeed, for all the potential good that community may provide its members, community is no substitute for justice, equality or respect. Community must be qualified.

This means that we need to underscore features of communities that are desirable. The idea is certainly contentious, for to outline such features risks 
being overly normative or prescriptive from the privileged perspective of three relatively affluent, White, middle class and (with one slightly younger exception) middle-aged men. Nevertheless, it strikes us as uncontroversial to say that communities comprised of gangs of young people who engage in violence may provide their members with a place to belong and yet fail altogether to foster outcomes favourable to the well-being of others, if not also to their own members. Other communities, as we have just seen, may be good for some of its (more dominant) members but augur poorly for its more vulnerable members. There will be dispute about a host of other factors. Yet in what follows, we attempt to highlight what we believe to be four essential - and hence defendable - features of communities.

First, communities are about commonality. They serve to facilitate things that its members ostensibly share in common: a language, religion, culture, set of mutual concerns and so on. In fact, it would be accurate to say that a certain degree of homogeneity 'thickens' community life. Although communities will contain internal variation, considering that communities typically are organized around shared values, interests and goals, it would be surprising if 'deep diversity' was much in evidence. In other words, communities generally do not represent some cross-section of the larger population, especially when that community forms and comes together in particular places or locations that create a shared space and help to reinforce the defining features of the community.

Second, for communities to be robust and viable, they will supply crucially important enabling conditions. Enabling conditions can begin with something as deceptively simple as having a place to belong, to feel accepted, to call home. As sources of shelter and intimacy, communities typically supply the basic social and psychological resources necessary to flourish. But communities - in the geographically bounded sense, at least - also need to provide the social, material and economic resources for flourishing. Strong communities must have stable institutions (governments, churches and schools), provide resources for parents and children (parks and libraries), facilitate (even if by proximity) economic opportunities and, finally, social networks and capable leaders. Taken together, the psychological and material aspects of community can serve as baseline necessities for individual well-being and communal health.

Third, for a community to be robust and viable, its entrance and exit requirements must not be unduly restrictive. Communities lacking this requirement will be less likely to foster well-being for their members as well as those characteristics of community that are essential for the cultivation of virtue. Communities therefore need more than the 'thickness' of shared beliefs, interests and purposes; they also need boundaries that are porous, walls thin enough to allow their members to come and go as they please. This is not to understate the extent to which community members' identities may be profoundly shaped by the features of 'their' respective communities. Rather, the point is that enabling communities must not unduly coerce or restrict what their members are permitted to do. They should not be oppressive.

These mobility conditions lead us to the fourth condition, namely, communities ought to produce virtue. To assess the virtue of a community, we will want to know what kinds of interests, experiences and goals are being shared. Only a moral relativist would argue that differences between communities are unimportant and that, say, a community of neighbourhood volunteers whose shared purposes include feeding the disabled and elderly is on a moral par with, say, a community of nudists, whose aims and purposes principally are to enjoy the liberties of not wearing clothing. Whilst it may be said that both possess community-like characteristics, both cannot be said to produce comparable virtue.

\section{Community and virtue}

As we have seen, being a part of a community will provide many benefits for its members, among them a feeling of acceptance or belonging. In addition, we have suggested that strong and healthy communities also will produce virtue. By virtue we mean to indicate good or admirable qualities or properties of persons. In its usual Aristotelian sense, virtue denotes a disposition or habit that has been achieved through 
effort and practice. Virtue may include traits such as courage, honesty, self-discipline, compassion, loyalty, generosity and respect. Virtue will involve the cultivation of dispositions, habits and actions whose value promotes individual and collective well-being (Nussbaum, 1988). To say something about a person's virtues is also to say something about his/her character, and persons who consciously cultivate the virtues may be said to live a life of greater moral excellence than those who do not.

But virtues also have a communal dimension. 'Communal virtue' can only arise out of a situated and hence spatialized - set of practices that are ongoing, complex and relational. That is to say, the aims, purposes and even identities of community members are forged, even as they remain fluid and are redefined, through engaging in shared practices and interactions with others within the community. As is often the case, those shared practices have a shared history and also may be unified by a shared vision of the good (MacIntyre, 1981). Communal virtue produces what Putnam (2007) has called bonding capital: shared interests and projects with others like oneself, producing a sense of group cohesion and belonging attractive to its members. The cultivation of communal virtue is often facilitated by local and fairly homogeneous networks where social trust is strongest. To put it another way, there are also spatial benefits to the concentration of virtues.

Yet robust communal virtues will not be contained within specific groups or locations; indeed, inward-looking bonding forms of virtue do not exclude outward-looking or bridging virtues. To illustrate, bonding capital may lead to the building of community centres, parks, schools and libraries; yet these also facilitate bridging capital to the extent that they are shared with, and benefit, others. Further, the benefits of a neighbourhood watch programme that shares the responsibility for safe and congenial relations among community members may very well expand outward to adjoining neighbourhoods, where the relevant virtues can be emulated by others. How much bridging potential the relevant virtues have will depend, in part, on their efficacy and reach; how broad the scope of 'common' good is will arguably depend on the good being promoted (Merry, 2013). Whatever the case, the effects of communal virtue will be felt first and foremost near their source: the immediate context in which the relevant virtues and activities are cultivated.

Strong communities, then, supply belonging but also virtue. Those lacking in virtue still may offer a sense of belonging, that is, comfort and solace from the burdens of isolation and alienation. Yet if our specific group memberships are lacking in communal virtue, if they inhibit us from responding to the needs of others, or from acting in concert with others irrespective of shared beliefs and habits, then the value of that community - for outsiders at any rate - will, we argue, be doubtful. In what circumstances do the marginalized and stigmatized White poor in Britain possess the enabling conditions required to foster the 'virtuous community' (Rose, 2000)? That is the question before us.

\section{White poverty and social exclusion}

During the past 40 years by many estimates, a significant portion of what once was called the White working class has continued to slide further down the socio-economic ladder into less respectable status. Variously dubbed 'working poor', 'the marginalized', and even 'the underclass', the present state of affairs looks rather bleak (Buckingham, 1999; Hancock and Mooney, 2013; Skeggs, 1997). ${ }^{6}$ Recent economic trends have effectively precipitated a marginalized social position for hundreds of thousands of working-class background in an economy that increasingly is technology driven. White males have been hit particularly hard (relative to their previous position as 'breadwinners') but women, too, must compete for entry-level service positions with low remunerative value and little job security. The consequence has been a pervasive social malaise in many previously robust and proud working-class communities.

Among scholars documenting these changes, there is little disagreement that the position of relative strength White working-class Britons once enjoyed has been profoundly eroded. Indeed, in many locations, the once strong pride defined by regional, working-class or even religious identities 
has virtually disappeared. As the presence of legitimate employment opportunities have slowly dried up over the past three decades, community life has eroded. Council estates in many quarters increasingly have suffered from neglect and underinvestment, and unemployment and criminality too often have usurped gainful employment that already was in scarce supply. Drawing upon the rhetoric of a 'broken Britain', government officials and media pundits routinely stigmatize council estates and depict their inhabitants as work adverse skivers (Flint, 2003; Hanley, 2007; Valentine and Harris, 2014). For example, the right-wing paper, The Daily Mail, published an article online on 23 June 2012, entitled 'Cameron to axe housing benefits for feckless under $25 \mathrm{~s}$ as he declares war on welfare culture' (Walters, 2012).

The plight of the British White poor in the 21st century is very much affected by involuntary chiefly economic - forces beyond their control, which both restricts the options available to them and eat away at self-respect. Haylett (2001: 353) describes how most media and even some academic depictions of this disparate group unsurprisingly are marked by 'positions of disparagement or retreat from people who are seen to embody an unsettling mix of whiteness, "working-classness," and poverty. Frequently these [descriptions] are marked by silences which speak of disappointment, embarrassment, and abandonment'. Contempt for the White poor - concerning their habits, modes of dress, speech patterns, types of work and places of residence - serves to reinforce a sense of entitlement as well as an insurmountable cultural and social class divide between the haves and have-nots. Even when silence $i s$ interrupted by public commentary, derision of the White poor continues to have widespread currency. ${ }^{7}$

Yet whilst it has taken on a more insistent tone in the past 20 years, ridicule and dismissal of a demographic category for class-related markers is not something new. Indeed, the history of British White lower-class stigma runs much deeper than that which coincides with an unfortunate downturn in the economy. It can be argued that this social class history provides the long-standing foundation upon which current stigma of being poor and White rests
(Bonnett, 1998; Jones, 2012; Lawler, 2012; Reay et al., 2011).

The problems associated with stigma and disadvantage come into even sharper focus once we consider the educational predicament of poor White children. For years, the situation in British schools for this demographic category has been rather bleak. Like disadvantaged children elsewhere, poor White children are more likely to experience educational disadvantages, fewer role models and to find curricular silence with respect to their own social class background, community and history. During the past few years, considerable media attention has argued that poor Whites (and boys in particular) were the lowest-achieving demographic category in Britain. ${ }^{8}$ Taken together, poor White children are more likely to have levelled aspirations, and a significant percentage drop out of school without five General Certificate for Secondary Education (GCSEs) - the English equivalent of a high school diploma (Dunne and Gazeley 2008; Ingram, 2009). Explanations for school failure move in different directions, but they frequently circle back to the environments in which young people are growing up: 'problem estates' with high unemployment, addiction, gang culture, inhabitants with low aspirations and general aimlessness. In short, both the community and home culture are held culpable for the failure of poor White children. ${ }^{9}$ Moreover, consistent with a conservative ideology that extols individual responsibility for success and failure, many poor British White youth who do badly at school internalize the view that they have only themselves to blame. Hence their failure merely confirms what many others already think of them namely, that they are expendable.

The position of poor and marginalized Whites has not gone unnoticed. Left-leaning academics and journalists periodically express outrage about their plight. Yet whilst the outrage and concern is a welcome salve to the more common vitriol and neglect, these sentiments of intellectual solidarity do little to offset the plight of the disadvantaged. Stephen Lawler (2012: 418) astutely observes:

The point is not whether or not the [left-leaning] middle-classes are well-meaning, but whether they enjoy privileges that mean they can claim valuable 
characteristics such as progressiveness as part of their selves. Clearly there are conflicts and ambivalences going on within the middle-class, as within all classes. But this should not blind us to the ways in which it is middle-class people who are able to claim a monopoly on the normal and are in a position to make judgments and to make them stick.

Given the depth and breadth of the challenges facing the White poor, a number of questions arise. First, what are the appropriate responses available to the public? Second, what options are there for the White poor, and can they decide on their own terms what kinds of communities they wish to have? Are there possibilities for meaningful community, and do any of these provide the enabling conditions necessary for producing the relevant virtues? And finally, what are the circumstances in which poor and stigmatized communities mobilize in their own interests against the difficulties that they face?

\section{Responses}

\section{Moralism}

By far the response most often heard is a moralistic one, which is to say that the poor generally, and poor Whites specifically, suffer from marginalization because their members possess damning character flaws (not usually presumed to arise from genetic inheritance but from their social upbringing). In contrast to the former working classes for whom the work ethic was a primary identifier of self and community, with the White poor there is an alleged absence of the same. (Conservatives have long seized upon the welfare state as singularly responsible for this, see Valentine and Harris, 2014). However, the White poor also seem to lack both the community-based networks and economic opportunities others ostensibly possess. Accordingly, many believe that community, in any meaningful sense, is simply not an option for this group owing to an absence of enabling conditions (including a lack of positive role models for the young). In short, the poor largely are to blame for their own problems exacerbated by an intergenerational transfer of cultures of dependency - and their bad choices are simply corrosive to whatever thin fabric of community remains. Because conservatives are inclined to believe that the poor are in some sense responsible for the difficulties they face, there is much talk about the breakdown of families, an absence of morals, and the prevalence of antisocial behaviour. Absent fathers are singled out for condemnation, as are lone female parents (witness Charles Murray's writings of the late 1980s and early 1990s). Where members of this group are also welfare recipients, as they often will be, the political assumption is that they have a tendency or predisposition against working - that, for this group, the welfare system is less a safety net than a comfortable hammock. The political response is therefore to lessen and to restrict welfare payments, to 'encourage', cajole or force people back to work.

On this logic, poor communities can only produce failure and despair, largely because its members lack a work ethic but also the civic virtues and cultural and social capital necessary to rise above their station. This view has a long history in the social sciences; in social policy it goes back to the poor laws, which drew a distinction between the deserving and undeserving poor. The problem with this diagnosis is that it tends to locate the source of the problem exclusively in the attitudes, behaviours, dispositions and choices of the poor themselves. A diagnosis of this kind engages in a tactic of blaming - and stigmatizing - those who are in a situation not always (or not entirely) of their own making (McIntyre and McKee, 2008; Orwell, 1937), ignoring the structural and institutional features in the environment that influence and shape how individuals act.

\section{Structuralism}

A very different type of response, one generally favoured by the more politically left-of-centre, is to say that members of the socially excluded White poor are not themselves to blame but are the victims of an unjust economic system, social inequalities and inequalities of opportunity that have in a neoliberal climate of competition and unequal choice rendered them vulnerable to a globalized economy, unregulated markets and a retreating welfare state. Exacerbating these structural factors are cultural and social classism that stigmatize and discriminate. 
Accordingly, the disadvantage that the White poor embody can only be remedied when we adopt policies whose aim is to promote social justice, be it by the more equitable distribution of resources or by improving opportunities for the socially and economically excluded.

Doubtless certain policies (e.g. guaranteed basic income) can have a significant impact on poverty and its related ills. Equitable funding and staffing of early education programs and schools, reliable public transportation, community-based policing practices and affordable food and health care available to all go a long way to expanding the opportunity structures - or providing the enabling conditions - for society's less fortunate. Advocates of this response often favour the disruption of concentrated poverty and aspire to a future of better integrated neighbourhoods and schools.

However, policies that might achieve this are generally asymmetric: broadly they entail moving poor children away from their neighbourhoods into 'better' environments where an optimistic belief is maintained that the privileges of other children and their families will 'rub off' on them. However, within the empirical literature, there is little agreement whether or not such strategies can or could work and even when apparently set within an experimental design such as the Moving to Opportunities (MTO) Programme in the United States, where the moving into supposedly better environments has rarely brought the gains presupposed (an exposition of the MTO and associated programmes is beyond the scope of this article, but DeLuca et al., 2012 provide a good starting place for exploring the programme and outcomes. See also Clark, 2008).

With its attention to structural features shaping choice and opportunity, this approach represents a different type of diagnosis, but the problems it create arguably are just as serious. First, given the scope of globalized capitalism, structuralist arguments may be naive for what they aim to remedy when labour markets are not confined to national borders, schools available to the poor are not adequately resourced, employers increasingly offer short-term contracts and part-time work, and there is poor access to well-remunerated jobs within deprived neighbourhoods. Second, notwithstanding many of the problems and challenges endemic to poor neighbourhoods, structuralist explanations consistently undervalue the attachment poor residents have to their own neighbourhoods (Goetz, 2003; Sharkey, 2013; Slater, 2013). Further, advocates of a structuralist response at times seem to engage in a dogma of victimology inasmuch as they imply that the poor bear little responsibility for any choices that they make or are inherently incapable of doing anything for themselves; rather, it must be done for them. This response, then, risks engaging in morally objectionable expressions of paternalism that assume from the outset that poor Whites must receive their self-respect from being in proximity with more fortunate others. In short, a purely structuralist approach operates on the assumption that the poor largely are incapable of producing their own robust communities with the relevant enabling conditions and communal virtues.

But are these two polarizing interpretations the only options available or is the polarization, in fact, part of the problem? Julia Unwin, Chief Executive of the Joseph Rowntree Foundation and the Joseph Rowntree Housing Trust, argues that the dichotomy gets in the way of a common-sense pragmatism that recognizes elements of both positions are true and need to be acknowledged as such if effective solutions to fight poverty are to be found (Unwin, 2013). We agree, and so aim, to push past the oversimplifying dichotomy in search of a more nuanced alternative. In the following sections, we explore whether community virtue - capable of both bonding and bridging capital - remains an option for the stigmatized White poor in Britain and, if so, what it might look like.

\section{In search of a viable community for the White poor}

How else might community be imagined, and are there viable options available, ones capable of overcoming the stigma of membership in a marginalized group? More importantly, are there varieties of community that are capable of supplying a number of crucial enabling conditions necessary for redefining, reclaiming and redirecting (Merry, 2013) what it means to belong to a White, poor and stigmatized 
demographic group? In what follows, we consider two familiar sources of community bonding that have waned in influence. We then move on to consider three imagined alternatives and ask whether any of them can feasibly supply community for the British White poor.

\section{Religion}

In many minority communities, perhaps especially for immigrant groups, religion often plays an important role in binding ethnic minorities together. A rapid expansion in the previous decades of Jewish, Sikh, Hindu, Christian and especially Islamic community centres, places of worship and schools has 'thickened' the institutional landscape in scores of communities across Britain. Yet despite the continued thriving existence of thousands of Anglican and Catholic community centres, churches and schools (often attended by non-members of the religious group), across Great Britain, the role of religion generally in community life has dramatically waned in significance as a source and inspiration for large numbers of citizens. ${ }^{10}$ The same is true in the case of the White poor. So whilst religion continues to play an important communal role for various ethnic minority groups, the same is no longer true for the White poor. Moreover, whilst many continue to attend religious schools, increasingly Anglican and Roman Catholic schools have become markers of middle-class distinction (Allen and West, 2011; Gibbons and Silva, 2011; Harris, 2012). Hence with few exceptions, religion does not provide the same binding support that it once did for the White poor.

\section{Trade unions}

Similarly, trade union membership for hundreds of thousands of primarily male workers across Britain not only supplied a decent wage and attending benefits but also a sense of solidarity with others and a sense of self-respect. However, precipitated by the inexorable decline of heavy manufacturing, mining and industry across Britain and elsewhere, membership in trade unions has dropped off dramatically. Once a reliable marker of a proud and workingclass identity, steady deindustrialization, global commerce and neo-liberal economic policies have helped to undermine the once seemingly unassailable strength of trade unions. Indeed, when compared to their pre-Thatcher influence, the strength of trade unions outside of the public sector has been emasculated.

If, then, these two features of community life once vibrant and fortifying to a working-class identity - have been lost, are there alternatives available to the White poor that might supply the enabling conditions necessary for fostering self-respect, community virtue and both bonding and bridging capital? Or are the possibilities for the moment non-existent? To explore this, we construct two artificial social arrangements recognizable to most readers. We describe and examine each and ask whether either of them is capable of supplying both the bonding and bridging capital necessary to satisfy the community standard we have outlined. We are aware that our typologies risk being caricatures. Yet the purpose they serve is not to capture any empirical reality but rather to enable an imaginative analysis of community. We begin with the weakest variant of community imaginable for (certain) members of the marginalized British White poor. We then examine a more institutionalized variant and ask the same questions. Finding both deficient, we then go on to explore a third and fourth possibility and ask in what these might consist.

'Loiterers'. For our first type of 'community', consider a common sight on many a street corner throughout the British Isles: young men in hoodies, baggy trousers and trainers messing about. ${ }^{11}$ The young men range in age from 16 to 25 , and there seems to be a hierarchy within the group apparent to anyone who studies their behaviour and activities. On the whole, most passers-by find them to be a nuisance and avoid them if they can. Occasionally, there are hostile verbal exchanges with others who may happen by and cast an unwelcome glance or remark in their direction. Typically, they simply loiter on the street corner for what seem like long stretches of each day, pushing off when the police come near or when the weather turns nasty. Most of the time they do not get up to much, but occasionally there is trouble. In some places, they are 
unwelcome - some small businesses install 'mosquito' devices to keep the group away.

What kind of a community is this? Certainly there is commonality: members of the group clearly value the sense of belonging that they gain from being one of the loiterers. There also is friendship and there is loyalty. The loyalty appears to be expressed by a code of values shared by all and crucial to the group's cohesion: stand up for the others if there's trouble with outsiders, divide the spoils and absolutely no ratting on each other. The bonding in this example also appears to be intrinsically local. Whilst perhaps of dubious value to non-members, there clearly are elements present that are important for group bonding. However 'thin' relative to other forms of group membership, being a member of the loiterers offers young men a place to belong, it increases a sense of self-respect, involves sacrifice and concern for each other and encourages allegiance. In short, whilst there is no denying that this group is deprived relative to those with more education or a more advantageous socio-economic position, there nevertheless are unmistakable bonds present. In our judgement, it would be a mistake to ignore or discount these.

But is there much virtue present? Moreover, are essential enabling conditions present that contribute to overall well-being? Neither seems to be the case. Take the latter first. In most cases, loiterers become loiterers precisely because there is an absence of enabling conditions. Certainly there is a sense in which its members have a place to belong, even if that belonging is defined by an absence of other community-like features. But in most cases there is not adequate employment and income; intimacy, too, is tenuously provided by belonging to a group of 'outsiders'.

Or consider the matter of communal virtue. Notice that the foundations upon which this bonding among the loiterers is built is pretty thin. If there is a reason that young White males occupy street corners to pass the time of day it is because they often have nothing better to do. Indeed, it may be conjectured that such groups largely would not exist were other enabling conditions - notably meaningful and remunerative employment - present. With respect to bonding virtue, even if the loiterers' communal bonds are able to produce some necessary virtues say, courage or loyalty - and promote some important goods for the group and its members, too many other virtues are absent. For starters, exiting the community often is not an option for young boys, if doing so exposes one to bulling or violence. Further, as we have seen, communal bonds should be capable of producing 'bridging capital' too. That is to say, virtues the group produces should also enable its members to join up with non-members in various ways to produce virtues on a broader, and more civic, scale. Communal virtues such as good will, respect and empathy will contribute to, and strengthen, the broader civic good. The loiterers seem capable of producing certain virtues that arise from the cohesive bonds of their community, but it does not inspire confidence that these will foster much more than self-interested outcomes. This form of community will not get us far.

'Nationalists'. Our second type of community represents a specific response to years of frustration and outrage among the White poor about the lack of schools offering an adequately challenging education, as well as bleak employment prospects and increasingly unaffordable housing conditions. Moral judgement heaped upon a socio-economically disadvantaged, though indigenous group, combined with a battered sense of communal identity and eroded self-respect, frequently yields defensiveness and hostility not only towards the middle classes but also to anyone perceived to occupy a more advantaged position. Replacing once proud and distinctive working-class modes of belonging, new group identities increasingly involve reconstructing what it means to be British (i.e. satisfying the condition of being all of White, Christian and native English background) in contrast to others (i.e. typically immigrant and ethnic minority, but increasingly Eastern European as well).

Against the inexorable downward social and economic spiral for the working classes since the early 1980s, many (e.g. the UK Independence Party and its leaders) routinely argue for limiting immigration. Others have attempted to slow or reverse this trend by channelling disaffection and rage onto those perceived to be gaining at their expense. Anti-immigrant and 
even overtly racist organizations and political parties have witnessed a resurgence since the 1970s. At times, the British National Party (BNP), the English Defence League (EDL) and, more recently (on social media, at least), the so-called Britain First have stepped into the void, claiming to proudly maintain and perpetuate strong communal ties for disenfranchised Whites excluded from the language of multiculturalism. Moreover, each aims to reinstate and reinvigorate what it means to have self-respect as a White marginalized class.

So what do we make of this response? Here we observe an institutionalized response to the demand for community. Neither the BNP nor the EDL is specifically focused on combating poverty and social exclusion. Yet in the empty space left behind by increasingly obsolete trade unions and organized religion, both groups have capitalized on a need for commonality by setting out to instil a sense of belonging, solidarity and nationalist pride for those willing to take up their cause. Their appeal - what remains of it - continues to resonate mainly with poor and marginalized whites. Moreover, their form of community is not restricted to the local context but extends to participants right across Britain. In this respect, we can recognize a response to social exclusion that draws upon many communal metaphors, among them identity, belonging and solidarity. Moreover, we see in these groups a degree of self-determination bent on addressing and promoting the interests of the White poor and working class.

But clearly there are problems here as well. For starters, these institutionalized responses to exclusion are themselves predicated on notions of exclusion. Whatever they may accomplish with respect to supplying certain enabling conditions necessary for community and self-respect, their bonding capital arguably is sown from the seeds of an exclusionary (and rather male-dominated) ethnocentrism. As such, this form of community violates the third condition of community, namely, that entrance and exit must be unencumbered. Perhaps most notably, vital sources of bridging capital are completely absent. Generally speaking, these movements are organized and motivated by what - and who - they are against. The nationalist response in Great Britain (and across
Europe for that matter) has in fact become a logical, if tragic, attempt to regain self-respect where so much self-respect has been lost to irrevocable changes in the economy as well as in the wider British culture. So whilst the nationalist response manages better than the loiterers with respect to bonding capital, it fails to produce the virtues bonding capital ought to have and neglects bridging capital altogether.

A tertium quid?. Recall that strong and viable communities need to produce virtues crucial to promoting individual and collective well-being. As we have seen, for members of many minority groups, there often are resources and enabling conditions present that derive from turning inward for support from one's group. In many cases, we witness both the bolstering of self-respect and the bonding and bridging capital we expect from communal life. Yet having seen two typologies of community fail in the foregoing paragraphs, in what follows, we posit two more spatially contained examples as cases for consideration. Owing to space limitations, we keep the empirical details brief, yet each moves us closer, we think, to examples of how even disadvantaged and stigmatized communities might mobilize to act in their own interests and promote communal virtue.

\section{Option 3}

Here our community is built around resistance and draws on the experience of a small village facing the threat of substantial new housing development. ${ }^{12}$ Being positioned near one of the major urban conurbations in the United Kingdom, our village has been identified as a key location in a wider development plan to deliver substantial housing growth. The population of the village is currently a little over 2500 people, and the proposed development will add over 750 houses to be built by private developers. The land on to which the development is to be built is owned by some of the largest landowners in the United Kingdom, further antagonizing the local community through the apparent imposition of a large development for which the plan and potential implementation has neither been sought nor extensively consulted. What we wish to focus on in this 
example is the composition of the community who are working together in order to form a network of resistance.

The current residents of the village include a wide diversity of people and households. There is a substantial number of workers from the nearby large urban conurbation as well as individuals employed more locally. There are professional as well as skilled and semi-skilled workers, and it is clear that representatives of all these groups participate in the resistance movement. Together, they appear to display what some have called collective efficacy, a combination of social cohesion and shared expectations among members of a community to a threat. That threat may be internal (e.g. crime) or external, as in this case with encroaching corporate influences. Either way, collective efficacy is undergirded by deeply shared expectations about public behaviour, as well as trust in the role that schools, business and local government can play in fostering and maintaining community cohesion. ${ }^{13}$ Interestingly, in this case, a strong and surprisingly heterogeneous opposition - comprised of both working- and middle-class residents in the local area - has developed in response to the threat of new development to the community living in the village.

We have been searching in this article for what we have termed a strong community for the White British poor. As we have seen, diversity is not a specific requirement, but shared values, interests and goals are. In this case, both are present. Marshalled against the imposition of the new housing development, there is a clear set of values, interests and goals: the preservation of the current village structure boundaries and, ultimately, what the locals define as their community. Moreover, there is commonality, for notwithstanding their many differences, there is a clearly defined set of allegiances that bind the individuals of this heterogeneous community together. Importantly, not all members of the village have to participate in the resistance movement; only a critical mass mobilized to resist on behalf of all is required. The resistance can take many forms. At one level, it involves collective responses to calls for consultation or position pieces by the developers or council representatives. At another level, it requires the engagement with opposing parties during meetings, ensuring that the collective view of the community is expressed and that the extent of the opposition is realized. Ultimately, whilst not all members need to actively participate, it is important that many do, demonstrating the common purpose and bonding that is present.

Further, the boundaries of the community are porous enough to enable movement into and out of the collective. Even so, what the community shares is a strong sense of place and belonging.

So far so good, and the positive attributes of this example with respect to our strong community continue to become apparent. The community clearly provides virtue of the relevant sort. It is a nonpolitical movement working towards the wellbeing of the current local group against the fear that a far larger conurbation will reduce the well-being of many current residents: by the increase in noise and traffic, the threat to locally run businesses as larger corporate groups move in and undercut local enterprise and the immediate impact on the housing market the new development would almost certainly have. Further, there is sufficient bonding and bridging capital available to strengthen their community and build alliances across social class differences.

However, whilst many of the criteria we outlined are satisfied, there is one key element missing: the community in question is not comprised solely of a disadvantaged group, namely, the White poor. To be sure, the community group satisfies many of our requirements with respect to commonality, enabling conditions, virtue and both bridging and bonding social capital. Yet the evidence, whilst clearly demonstrating the co-production of resistance across groups, still leaves intact the assumption that poor Whites are themselves fundamentally incapable of producing their own robust communities with the relevant enabling conditions and virtues. Indeed, the resistance movement appears even to require the input of external actors, even if these actors are working within the same setting. It would appear, then, that our example points more towards the efficacy of social and economic mixing rather than a self-determining community group. A further complication exists through the objectives of the opposition that may result in further disadvantage for the 'poor': without further construction 
of new properties the local housing market will continue to operate as is without an increase in supply of chapter housing. In line with many larger estate developments, a proportion (however small) of the development has to include 'affordable housing' - precisely the housing that would advantage the group with which we are concerned in this article. Thus, success for this community requires the further disadvantage of those similar to, but outside of, their current boundary.

\section{Option 4}

This brings us to a fourth alternative, incidentally also one of resistance. Here we examine a community whose identity became more sharply defined in response to the loss of a youth community centre. The 2008 financial crisis had devastating ramifications in many communities. Government spending has been cut in response to the increased pressures to reduce budget deficits to many of the welfare and social provisions that both national and local governments had previously financed. In many cases, front-line services such as social work, homeless and housing services and elderly care have been spared the large-scale cuts. However, other services, notably youth provisions, have not been so lucky. Hence our community is galvanized in its response to the budgetary cuts in an English town that would have resulted in the loss of its youth centre.

Faced with this institutional loss, the community basically had two responses. The first was merely to continue and hope that the change will not adversely impact the community too greatly. The second was to fight and resist the closure and then, when the closure could no longer be resisted, develop a response whereby the centre could become viable without support from central or local government. This is precisely what happened in our final example and notably in an area that is nationally recognized as being predominately White with low incomes and low levels of final education, thus satisfying our requirement that the community be comprised exclusively of the marginalized White poor. We exemplify this community using an example drawn from the actions of residents in a small market town in the South of England within the commuter belt of a larger county centre. This community was faced with the closure of their youth centre in 2011 as a result of the substantial cuts in funding. As a response to this, a community action group was formed and new sources of funding and sponsorship sought. ${ }^{14}$ Whilst the centre initially closed in 2012 , it reopened in early 2013, with new backing and being run by the local community. ${ }^{15}$

Unlike the previous example where resistance to village expansion involved a socially diverse community, here there are no professionals working outside the neighbourhood to bring in additional social capital. Nor are there any external bodies willing to provide support. Whilst the theory of collective efficacy describes 'expectations for action within a collectivity ${ }^{16}$ in the previous example, we saw how more privileged actors were needed to broker the effective resistance to corporate incursion. There the evidence called into question whether the poorer members of this community would be better or worse off in resisting the imposition of the development without the social capital of its profession members. But perhaps contrary to expectation, our fourth example also provides evidence of collective efficacy. Here the homogeneity of population combines with shared interests and concerns to head off a threat to the community by mobilizing the commercial and charity users of the club - including a provider of sports training and club services and a children's youth charity - to provide sponsorship necessary for the club to remain open. Not even widespread poverty and disadvantage can impede the galvanization of communal virtue necessary for tackling the challenges at hand. However, the substantial nature of the challenges faced by the community should not be underestimated and, at the time of writing, the youth club has been forced to close whilst the community mobilizes wider financing to enable the outright purchase of the facility for the community. Yet rather than view this as evidence that this form of community is also doomed from the outset we, instead, focus on the fact that despite substantial challenges the community is still working towards its original goal.

We also see evidence of enabling conditions necessary for strengthening community bonds and fostering communal virtue. In this case, the conditions 
included a sense around which the community was constructed and contain multiple individuals who when threatened with the loss of a resource were resolved they could take action to avoid an outcome that they did not want. Notwithstanding this, maintaining the enabling conditions remains an ongoing struggle, but their presence does not depend upon others providing it. Indeed, here is an example of a community turning inward in organization in order to create a response to disenfranchisement by resisting the imposition of budget cuts that will so devastatingly affect their community. What evidence we have - that 3 years after the initial removal of funding the community is still working to preserve their youth club - suggests that both the fabric of social ties in this community as well as the determination to hold onto an important community resource proved capable of mitigating being further disadvantaged.

\section{Conclusion: Whither communities for the White British poor?}

So where does this leave us? We have identified many forms of community represented in the lives of the marginalized White poor population. Many of these forms of community satisfy some, but not all, of the criteria we outlined. Remember that these criteria included commonality, the presence of enabling conditions, entrance and exit requirements and finally the ability to produce virtue. In each case we have explored there have been challenges: some represent communities that provide internal support but lack external validation; others are communities that involve the White poor and supply many of the apparent functions strong communities need to have. Still others fail because the very notion of community appears to require an explicit exclusion that rejects the possibility of bridging capital and also ultimately fails the bonding capital test as well.

For many readers, the third notion of communitythe small village facing the threat of a new housing development - is perhaps the most viable: here we witness a grouping that has all the criteria we delineated for a strong community. Unfortunately, the very strength of the resistance to outside forces appears to depend, at least in part, on the social capital its more privileged group members possess. Thus, whilst it does illustrate a community with highly functional bridging and bonding capital, it leaves the group in question - the White poor essentially dependent upon outside help.

Our fourth community manages to pull together and resist the cuts to their services by assuming responsibility for the service that was to be cut. Succeeding in this endeavour, it appears to be our most hopeful example of community that defies the odds. It certainly satisfies all of the criteria we laid out. It also demonstrates the potential that marginalized and stigmatized communities have to support themselves, foster communal virtue and collective efficacy. That is to say, as a low-income White community, it not only was best placed to evaluate the challenges they faced but it also showed itself capable of creating effective strategies necessary to mobilize on behalf of their own interests. What may be lacking in social or economic prosperity can be compensated for in other ways. To what extent it is more generally true that poor communities are able to decide on their own terms the course they wish to take and accordingly advocate for themselves (in the absence of outside help) cannot be determined in the abstract but must be decided on a case-by-case basis. The geography of a community may facilitate the presence of enabling conditions or it may not; much depends on whether bonds are actually formed in the location in question or elsewhere (Blokland, 2003; Van Eijk, 2010). The same may be said of the possibilities for communal virtue.

Two formidable challenges for these 'successful' examples of community remain. First, and certainly in the case of the third community, one involving a socio-economic mix of community members, there is an inescapable power gradient that can potentially undermine the self-determination of the poorer, and hence weaker, members. The disparity in power lends itself to paternalism on the one hand (e.g. 'we know what is good for you') and potential dependency on the other. The second and more vexing challenge is this: not even our most hopeful examples are able to tell us whether community with all the relevant criteria in tow - will survive once the impending crisis has passed. So long as a battle against an encroaching force can be waged, 
perhaps only for that long can a semblance of community be maintained. Indeed, the examples seem to suggest that unless there is permanent and ongoing conflict, community for poor Whites in 21 st-century Britain seems an improbable quest.

So should one despair about the White poor in Britain? To us the answer is no; despair has never been a recipe for moving forward. We have searched for examples of desirable community where the needs, interests and aims of the White poor can take shape and be pursued. However, identifying and locating communities in possession of the necessary enabling conditions has indeed been difficult. As we have shown, either-or explanations of their disadvantage will not suffice. The causes of poverty and disadvantage - but also stigma - clearly lie outside of the actors themselves. We must therefore avoid overly simplistic individualistic explanations for White disadvantage in the British context. At the same time, however, whilst it is necessary to avoid such moralizing, more must be done to resist an equally problematic tendency in the academic literature, which is to speak of the White poor as though they primarily are but victims to circumstance. Consequently, the White poor are frequently depicted as fundamentally unable to choose and act for themselves; effectively they are dependent upon others for aid. But this interpretation, too, risks failing to demonstrate respect towards the White poor inasmuch as it both normalizes middle-class status and correspondingly undervalues the attachment that many have to their own communities. Further, an overly structuralist approach risks discrediting class-based forms of solidarity and resistance among the oppressed that, history shows, has assisted in effectively challenging power structures, even on occasion wresting power away from those who have it. Hence any effective responses to the plight of the White poor cannot afford to ignore either the concerns of the White poor themselves or their (latent) potential for agency.

One of the questions that surely remains for us to contemplate is whether the inexorable rise of a consumer and leisure culture has slowly undermined what it means to belong to a community. Moreover, it certainly would be a waste of both money and potential if state aid were unwittingly to erode the social goods that community can provide. That outcome, however, is not inevitable. Welfare-based approaches can more imaginatively be designed that do more than simply pay the rent and groceries. The current difficulty of locating meaningful expressions of community for the White poor does not mean that possibilities do not, or could not, exist. Indeed, the present state of affairs only points to a need for fresh ideas, ones capable of redirecting state aid into perhaps new expressions of community that do not rely upon ephemeral threats from the outside, nor ignore what members of the White poor care about. Remember that other disadvantaged and stigmatized groups often have internal resources available to them, inter alia culture, religion, language and shared immigrant status. Combined with the relevant institutional supports, turning inward for many of these groups satisfies what we earlier referred to as enabling conditions. These enabling conditions are not without their difficulties and limitations; they cannot undo racism or negate the stigma others impose on them. At the same time, these enabling conditions certainly are able, at a minimum, to provide strategies for coping with hardship, and they also are frequently capable of producing virtue. That is not nothing. But there is reason to think that community can provide mechanisms not only for coping but also for upward mobility. For this to happen, intellectuals and policymakers need to assist in creating, supporting and sustaining positive modes of community capable of long-term impact.

\section{Declaration of Conflicting Interests}

The author(s) declared no potential conflicts of interest with respect to the research, authorship, and/or publication of this article.

\section{Funding}

The author(s) received no financial support for the research, authorship, and/or publication of this article.

\section{Notes}

1. http://www.channel4.com/programmes/benefitsstreet

2. Yet even assuming that the relevant education and skills were acquired, this is not likely to solve the bigger challenge, which is how to compete for scarce 
resources when one's qualifications today may not be enough to compete for the same corresponding opportunities - moreover in limited supply - tomorrow.

3. Here we refer to those not associated either with immigration after World War 2 from the formerly British and Asian colonies nor more recently from across Europe.

4. The example of humour around the use of hard drugs in St Ann's Nottingham as effectively retold by Lisa McKenzie (2015) is a prime example here of close bonding in a way that, from the outside, may appear confusing or divisive, as the author herself admits.

5. We do not enlist Putnam's problematic broader understanding of social capital, an excellent critique of which can be found in Law and Mooney (2006), organized around the wistful notion of the lost family view of social order when viewed through the lens of a Marxian understanding of capital or more widely in Portes and Vickstrom, 2011. In any case, because there is no one commonly accepted definition of social capital, for simplicity sake, we refer to the links, shared values and understandings in society that enable individuals and groups to trust each other and so work together. See OECD insights: human capital at: http://www.oecd.org/insights/37966934.pdf

6. Skeggs (1997) argues that members of the working class increasingly self-identify according to what they are not (i.e. an underclass). Also see the Iain Duncan Smith report, 'Breakthrough Britain' (2007), which refers to an 'underclass' and highlights the breakdown of British society on many levels. Available at: http://www.centreforsocialjustice.org. uk/publications/breakthrough-britain-chairmansoverview

7. The television programme hosted by Jeremy Kyle routinely brings on guests believed to represent the abhorrent 'White trash', much like Jerry Springer's program in the United States had done many years before.

8. 'Poor pupils fail to make the grade', Times (12 December 2008), p. 25; 'White boys on free meals fall further behind in GCSEs', Guardian (12 December 2008), pp. 20-21; 'Social class affects white pupils' exam results more than those of ethnic minorities', Guardian (3 September 2010), http://www. guardian.co.uk/education/2010/sep/03/social-classachievement-school.
9. Although persons who participated in the looting, arson, and public disorder during the 2011 riots did not come from just one group (Whites, Blacks and Asians were all involved), a rather conservative response was certainly to be expected in many of the comments of Prime Minister Cameron in August 2011. The destructive riots in a dozen British cities, he insisted, came down to bad attitudes, behaviour and choices. They signalled a 'moral collapse' of communities 'out of control' and a general absence of personal responsibility. Working hard and playing by the rules, he added, would allow almost anyone to succeed. Although very few questioned opportunistic hooliganism and brash criminality in the riots that year, a mantra repeated by many at the time was that parents had failed to do their job and that there was a need to promote a stronger sense of citizenship and common values.

10. To be sure, Catholic identity continues to be more robust in Scotland, and the Protestant-Catholic divide in Belfast continues to garner attention, but these - often politicized - religious identities represent exceptions to the general rule, particularly for England and Wales.

11. This description is but a construct meant to reflect a reality many of us would recognize in the real world. But the details we supply unavoidably rely on stereotypes, not documented features of actual persons.

12. This discussion is drawn from a real-world example. However, as it represents an ongoing case, the authors have elected to describe it without revealing the location or groups involved.

13. See inter Alia, Sampson (2012).

14. Dover Express (2011) http://www.dover-express.co. uk/Community-hatches-plan-rescue-youth-club/ story-13343699-detail/story.html

15. Aylesham Village Website (2012) http://www.ayleshamvillage.co.uk/village-news/youth-and-community-centre

16. See Sampson (2012: 153).

\section{References}

Allen R and West A (2011) Why do faith secondary schools have advantaged intakes? The relative importance of neighbourhood characteristics, social background and religious identification amongst parents. British Educational Research Journal 37(4): 691-712. 
Blokland T (2003) Urban Bonds: Social Relationships in an Inner City Neighbourhood. Cambridge: Polity.

Bonnett A (1998) How the British working class became white: the symbolic (re) formation of racialized capitalism. Journal of Historical Sociology 11(3): 316-340.

Buckingham A (1999) Is there an underclass in Britain? British Journal of Sociology 50(1): 49-75.

Clark WA (2008) Re-examining the moving to opportunity study and its contribution to changing the distribution of poverty and ethnic concentration. Demography 45(3): 515-535.

DeLuca S, Duncan GJ, Keels M, et al. (2012) The notable and the null: Using mixed methods to understand the diverse impacts of residential mobility programs. In: van Ham M, Manley D and Bailey N, et al. (eds) Neighbourhood Effects Research: New Perspectives. Netherlands: Springer, pp. 195-223.

Dunne M and Gazeley L (2008) Teachers, social class and underachievement. British Journal of Sociology of Education 29(5): 451-463.

Eisenberg A and Spinner-Halev J (eds) (2005) Minorities Within Minorities: Equality, Rights and Diversity. Cambridge: Cambridge University Press.

Flint J (2003) Housing and ethopolitics: constructing identities of active consumption and responsible community. Economy and Society 32: 611-629.

Gibbons S and Silva O (2011) Faith primary schools: better schools or better pupils? Journal of Labor Economics 29(3): 589-635.

Goetz EG (2003) Clearing the Way: Deconcentrating the Poor in Urban America. Washington: The Urban Institute.

Hancock L and Mooney G (2013) "Welfare Ghettoes" and the "broken society": territorial stigmatization in the contemporary UK. Housing, Theory and Society 30(1): 46-64.

Hancock L, Mooney G and Neal S (2012) Crisis social policy and the resilience of the concept of community. Critical Social Policy 32(3): 343-364.

Hanley L (2007) Estates: An Intimate History. London: Granta Books.

Harris R (2012) Local indices of segregation with application to social segregation between London's secondary schools, 2003 - 08/09. Environment and Planning A 44(3): 669-687.

Haylett C (2001) Illegitimate subjects? Abject whites, neoliberal modernisation, and middle-class multiculturalism. Environment and Planning D 19: 351-370.
Ingram N (2009) Working-class boys, educational success and the misrecognition of working-class culture. British Journal of Educational Psychology 30(4): 421-434.

Jones O (2012) Chavs: The Demonisation of the Working Class. London: Verso Books.

Law A and Mooney G (2006) The maladies of social capital I: the missing 'capital' in theories of social capital. Critique 34(2): 127-143.

Lawler S (2012) White like them: whiteness and anachronistic space in representations of the English white working class. Ethnicities 12(4): 409-426.

MacIntyre A (1981) After Virtue. London: Duckworth.

McIntyre Z and McKee K (2008) Governance and sustainability in Glasgow: connecting symbolic capital and housing consumption to regeneration. Area 40(4): 481-490.

McKenzie L (2015) Getting By: Estates, Class and Culture in Austerity Britain. Bristol: Policy Press.

Merry M (2013) Equality, Citizenship and Segregation. New York: Palgrave Macmillan.

Murray C, Phillips M and Lister R (1996) Charles Murray and the Underclass: The Developing Debate. London: CIVITAS.

Nussbaum M (1988) Non-relative virtues: an Aristotelian approach. Midwest Studies in Philosophy 13(1): 32-53.

Orwell G (1937) The Road to Wigan Pier. Harmondsworth: Penguin.

Portes A and Vickstrom E (2011) Diversity, social capital and cohesion. Annual Review of Sociology 37: 461-479.

Putnam R (2007) E pluribus unum: diversity and community in the twenty-first century. Scandinavian Political Studies 30(2): 137-174.

Reay D, Crozier G and James D (2011) White Middle Class Identities and Urban Schooling. Identity Studies in the Social Sciences. New York: Palgrave Macmillan.

Rose N (2000) Community, citizenship and the third way. American Behavioral Scientist 43(9): 1395-1411.

Sampson R (2012) Great American City: Chicago and the Enduring Neighborhood Effect. Chicago: University of Chicago Press.

Sharkey P (2013) Stuck in Place: Urban Neighbourhoods and the End of Progress Toward Racial Equality. Chicago: University of Chicago Press.

Slater T (2012) The myth of "broken Britain": welfare reform and the production of ignorance. Antipode 46(4): 948-969. 
Slater T (2013) Your life chances affect where you live: a critique of the 'cottage industry' of neighbourhood effects research. International Journal of Urban and Regional Research 37(2): 367-387.

Strike K (2010) Small Schools and Strong Communities: A Third Way of School Reform. New York: Teachers College Press.

Skeggs B (1997) Formations of Class \& Gender: Becoming Respectable. Vol. 51. London: Sage.

Unwin J (2013) Why Fight Poverty? London: London Publishing Partnership.

Valentine G and Harris C (2014) Strivers vs skivers: class prejudice and the demonisation of dependency in everyday life. Geoforum 53: 84-92.

Van Eijk G (2010) Does living in a poor neighbourhood result in network poverty? A study on local networks, locality-based relationships and neighbourhood settings. Journal of Housing and the Built Environment 25: 467-480.

Wacquant L (2008) Urban Outcasts. Towards a Sociology of Advanced Marginality. Cambridge: Polity.

Walters S (2012) Cameron to axe housing benefits for feckless under $25 \mathrm{~s}$ as he declares war on welfare culture. Daily Mail Online, June 23. Available at: http://www.dailymail.co.uk/news/article-2163773/ David-Cameron-axe-housing-benefits-feckless-25s-declares-war-welfare-culture.html (accessed April 3, 2014).

Welshman J (2013) Underclass: A History of the Excluded Since 1880. 2nd ed. London: Bloomsbury Academic.

Wilson J (1984) The Truly Disadvantaged: The Inner City, the Underclass, and Public Policy. Chicago: Chicago University Press. 